\title{
Resveratrol suppresses TGF- $\beta$-induced VEGF synthesis in osteoblasts: Inhibition of the p44/p42 MAPK and SAPK/JNK pathways
}

\author{
GEN KUROYANAGI $^{1,2}$, TAKANOBU OTSUKA ${ }^{1}$, NAOHIRO YAMAMOTO ${ }^{1,2}$, RIE MATSUSHIMA-NISHIWAKI ${ }^{2}$, \\ OSAMU KOZAWA ${ }^{2}$ and HARUHIKO TOKUDA ${ }^{2,3}$ \\ ${ }^{1}$ Department of Orthopedic Surgery, Nagoya City University Graduate School of Medical Sciences, Nagoya, Chubu 467-8601; \\ ${ }^{2}$ Department of Pharmacology, Gifu University Graduate School of Medicine, Gifu 501-1194; \\ ${ }^{3}$ Department of Clinical Laboratory, National Center for Geriatrics and Gerontology, Obu, Aichi 474-8511, Japan
}

Received February 26, 2015; Accepted March 19, 2015

DOI: $10.3892 /$ etm.2015.2389

\begin{abstract}
Resveratrol, which is found in grape and berry skins and red wine, is generally known to be beneficial for human health due to its anti-inflammation and antioxidant effects. We have recently reported that transforming growth factor- $\beta$ (TGF- $\beta$ ) stimulates vascular endothelial growth factor (VEGF) synthesis through Smad-independent pathways, such as the p38 mitogen-activated protein (MAP) kinase, p44/p42 MAP kinase and stress-activated protein kinase/c-Jun N-terminal kinase (SAPK/JNK) pathways, in osteoblast-like MC3T3-E1 cells. The aim of the present study was to investigate the effect of resveratrol on the TGF- $\beta$-induced VEGF synthesis and the mechanism in osteoblast-like MC3T3-E1 cells. Resveratrol significantly suppressed the TGF- $\beta$-stimulated release of VEGF and the VEGF mRNA expression levels. SRT1720, a synthetic sirtuin 1 (SIRT1) activator, also reduced the VEGF release and the mRNA levels. With regard to the intracellular signaling in the TGF- $\beta$-stimulated VEGF synthesis, resveratrol and SRT1720 significantly attenuated the phosphorylation of p44/p42 MAP kinase and SAPK/JNK stimulated by TGF- $\beta$; however, the TGF- $\beta$-induced phosphorylation of Smad2 and p38 MAP kinase was hardly affected by resveratrol or SRT1720. These results strongly suggest that the TGF- $\beta$-stimulated VEGF synthesis is suppressed by resveratrol through the inhibition of $\mathrm{p} 44 / \mathrm{p} 42$ MAP kinase and SAPK/JNK in osteoblasts, and that the suppressive effect is mediated, at least in part, via SIRT1 activation.
\end{abstract}

Correspondence to: Dr Haruhiko Tokuda, Department of Clinical Laboratory, National Center for Geriatrics and Gerontology, 35 Gengo, Morioka, Obu, Aichi 474-8511, Japan

E-mail: tokuda@ncgg.go.jp

Key words: resveratrol, transforming growth factor- $\beta$, vascular endothelial growth factor, osteoblast

\section{Introduction}

Skeletal strength and bone mineral homeostasis are strictly regulated by bone remodeling (1). The process of bone remodeling consists primarily of two functional events: Osteoblastic bone formation and osteoclastic bone resorption (2). The disruption of the bone remodeling process is considered to cause metabolic bone diseases, such as osteoporosis. Numerous humoral factors, such as cytokines and prostaglandins, have been shown to participate in the bone remodeling process (3).

Transforming growth factor- $\beta$ (TGF- $\beta$ ), which is a member of the TGF- $\beta$ superfamily that consists of $>40$ members, such as bone morphogenetic proteins (BMPs) and activin, is well recognized as a stimulator of osteoblastic bone formation $(4,5)$. TGF- $\beta$ stimulates the deposit of bone matrix and the proliferation of osteoblasts (5). TGF- $\beta$, which is produced by osteoblasts and subsequently embedded into the bone matrix, is released and activated via osteoclastic bone resorption, the first stage of bone remodeling $(5,6)$. Thus, TGF- $\beta$ is fundamental for the regulation of bone remodeling, acting as a coupling factor between bone resorption and bone formation (7).

Vascular endothelial growth factor (VEGF) plays an essential role in angiogenesis (8). The osteoblast lineage is currently considered to be an important source of VEGF among bone cells (8). It has been demonstrated that VEGF receptors are expressed by osteoblasts and osteoclasts (8). A variety of physiological stimuli, including hormonal, mechanical and environmental factors, reportedly modulate the production of VEGF by osteoblasts, suggesting that osteoblast-synthesized VEGF is important for the autocoid-mediated control of angiogenesis in bone (8). We have previously demonstrated that VEGF synthesis in osteoblast-like MC3T3-E1 cells is stimulated by TGF- $\beta$ and positively regulated by $\mathrm{p} 38$ mitogen-activated protein (MAP) kinase, p44/p42 MAP kinase and stress-activated protein kinase/c-Jun N-terminal kinase (SAPK/JNK) $(9,10)$; however, the details underlying VEGF synthesis in osteoblasts are yet to be clarified.

Resveratrol is a polyphenolic compound found in grape and berry skins and red wine. It is currently believed that the various biological abilities of resveratrol mainly stem 
from its antioxidant and anti-inflammatory effects, which are mediated via the activation of sirtuin 1 (SIRT1) $(11,12)$. Low mortality rates from coronary heart disease have been reported in France, where there is frequent consumption of red wine (13). Since red wine is an abundant source of resveratrol, the so-called French paradox is considered to be associated with the uptake of resveratrol (13). In the matter of bone health, it has recently been reported that the risk of hip fracture in women who have a preference for wine consumption is lower than that in female former drinkers, non-drinkers or drinkers with different alcoholic beverage preferences (14). It has also recently been observed that resveratrol inhibits the BMP-4-induced VEGF synthesis via the suppression of the p70 S6 kinase in osteoblast-like MC3T3-E1 cells (15). In addition, we previously demonstrated that resveratrol attenuates the osteoprotegerin synthesis stimulated by prostaglandin $\mathrm{F}_{20}$ $\left(\mathrm{PGF}_{2 \alpha}\right)$ or $\mathrm{PGD}_{2}$ in MC3T3-E1 cells $(16,17)$; however, the exact mechanism by which bone metabolism is affected by resveratrol remains to be elucidated. The aim of the present study, therefore, was to investigate the effect of resveratrol on the TGF- $\beta$-induced VEGF synthesis and the mechanism in osteoblast-like MC3T3-E1 cells.

\section{Materials and methods}

Materials. Resveratrol and SRT1720 were obtained from Calbiochem-Novabiochem Corp. (La Jolla, CA, USA). TGF- $\beta$ and mouse VEGF enzyme-linked immunosorbent assay (ELISA) kits were obtained from R\&D Systems, Inc. (Minneapolis, MN, USA). Rabbit polyclonal phospho-specific Smad2 (\#3101), Smad2/3 (\#3102), p38 MAP kinase (\#9212), phospho-specific p44/p42 MAP kinase (\#9101), p44/p42 MAP kinase (\#9102), SAPK/JNK (\#9252), and rabbit monoclonal phospho-specific p38 MAPkinase (\#4511) and phospho-specific SAPK/JNK (\#4671) antibodies were obtained from Cell Signaling Technology, Inc. (Beverly, MA, USA). An enhanced chemiluminescence (ECL) western blotting detection system was obtained from GE Healthcare (Little Chalfont, UK). The rest of the chemicals and materials were purchased from commercial sources. Resveratrol and SRT1720 were dissolved in dimethyl sulfoxide, the maximum concentration of which did not exceed $0.1 \%$ and affected neither the assay for VEGF nor the detection of the protein level using western blotting.

Cell culture. The cloned osteoblast-like MC3T3-E1 cells were derived from a newborn mouse calvaria (18) and were maintained as previously described (19). Briefly, the cell culture was performed using $\alpha$-minimum essential medium $(\alpha-\mathrm{MEM})$, which contained $10 \%$ fetal bovine serum (FBS), at $37^{\circ} \mathrm{C}$ in a humidified atmosphere of $5 \% \mathrm{CO}_{2} / 95 \%$ air. The cells were seeded into 35 - or $90-\mathrm{mm}$ diameter dishes $\left(5 \times 10^{4}\right.$ and $2 \times 10^{5}$ cells/dish, respectively) in $\alpha$-MEM containing $10 \%$ FBS. Five days later, the medium was exchanged for $\alpha$-MEM containing $0.3 \%$ FBS. Experiments with the cells were performed after $48 \mathrm{~h}$.

Assay for VEGF. The cultured cells were pretreated with a variety of resveratrol doses $(0-50 \mu \mathrm{M})$ or SRT1720 for $60 \mathrm{~min}$ and then stimulated by $5 \mathrm{ng} / \mathrm{ml} \mathrm{TGF}-\beta$ or vehicle in $1 \mathrm{ml} \alpha$-MEM containing $0.3 \%$ FBS for the indicated periods.
Following incubation, the conditioned medium was collected and the VEGF concentration was measured using the VEGF ELISA kit, according to the manufacturer's instructions (R\&D Systems, Inc.).

Reverse transcription-quantitative polymerase chain reaction $(R T-q P C R)$. The cultured cells were pretreated with $50 \mu \mathrm{M}$ resveratrol, $10 \mu \mathrm{M}$ SRT1720 or vehicle for $60 \mathrm{~min}$, and were subsequently stimulated by $5 \mathrm{ng} / \mathrm{ml}$ TGF- $\beta$ or vehicle in $\alpha$-MEM containing $0.3 \%$ FBS for $12 \mathrm{~h}$. TRIzol ${ }^{\circledR}$ reagent (Invitrogen Life Technologies, Carlsbad, CA, USA) and the Omniscript ${ }^{\circledR}$ RT kit (Qiagen Inc., Valencia, CA, USA) were used for the isolation of the total RNA and its transcription into complementary DNA, respectively. The RT-qPCR was performed in capillaries using a LightCycler ${ }^{\circledR}$ system and the FastStart DNA Master SYBR Green I provided with the kit (Roche Diagnostics, Basel, Switzerland). The mouse VEGF and GAPDH mRNA sense and antisense primers were synthesized based on the method described in the study by Simpson et al (20). A melting curve analysis and agarose electrophoresis were used to evaluate the amplified products. GAPDH mRNA levels were used to normalize the levels of VEGF mRNA.

Western blot analysis. The cultured cells were pretreated with a variety of doses of resveratrol or $20 \mu \mathrm{M}$ SRT1720 for $60 \mathrm{~min}$, and were then stimulated by $5 \mathrm{ng} / \mathrm{ml}$ TGF- $\beta$ in $\alpha$-MEM containing $0.3 \%$ FBS for the indicated periods. The cells were washed twice with phosphate-buffered saline and then lysed, homogenized and sonicated in a lysis buffer that contained $2 \%$ sodium dodecyl sulfate (SDS), $50 \mathrm{mM}$ dithiothreitol, $62.5 \mathrm{mM}$ Tris/ $\mathrm{HCl}$ (pH 6.8) and 10\% glycerol. SDS-polyacrylamide gel electrophoresis was performed using the method of Laemmli (21) in $10 \%$ polyacrylamide gels. The protein was separated and transferred onto an Immun-Blot ${ }^{\circledR}$ polyvinylidene difluoride (PVDF) membrane (Bio-Rad, Hercules, CA, USA). The membrane was blocked using 5\% skimmed, dried milk in Tris-buffered saline-Tween 20 [TBS-T; 20 mM Tris- $\mathrm{HCl}$ (pH 7.6), $137 \mathrm{mM}$ $\mathrm{NaCl}$ and $0.1 \%$ Tween 20] for $1 \mathrm{~h}$ prior to incubation with the primary antibody. Western blotting was performed as previously described (22), using primary antibodies against phospho-specific Smad2, Smad2/3, phospho-specific p38 MAP kinase, p38 MAP kinase, phospho-specific p44/p42 MAP kinase, p44/p42 MAP kinase, phospho-specific SAPK/JNK or SAPK/JNK, with peroxidase-labeled goat-anti rabbit immunoglobulin G secondary antibodies (Kirkegaard \& Perry Laboratories, Inc., Gaithersburg, MD, USA). The primary and secondary antibodies were diluted at 1:1,000 with 5\% skimmed, dried milk in TBS-T. Visualization of the peroxidase activity on the membrane was performed using X-ray film and the ECL western blotting detection system.

Densitometric analysis. A scanner and image analysis software (ImageJ version 1.47; National Institutes of Health, Bethesda, MD, USA) were used to perform densitometric analysis. The phosphorylated protein levels were presented as the fold increase relative to the unstimulated control cell values and calculated by normalizing the background-subtracted signal intensity of each phosphorylation signal to the respective total protein signal. 
Statistical analysis. Data analysis was performed using analysis of variance, followed by the Bonferroni method for multiple comparisons between pairs. $\mathrm{P}<0.05$ was considered to indicate a statistically significant difference. All data are presented as the mean \pm standard error of the mean of triplicate determinations from three independent cell preparations.

\section{Results}

Effect of resveratrol on the TGF- $\beta$-stimulated VEGF release in MC3T3-E1 cells. The effect of resveratrol on the TGF- $\beta$-stimulated VEGF release in osteoblast-like MC3T3-E1 cells was firstly examined. Resveratrol, which alone had little effect on the VEGF release, significantly reduced the TGF- $\beta$-stimulated VEGF release in a time-dependent manner up to $48 \mathrm{~h}$ (Fig. 1). The suppressive effect of resveratrol on the TGF- $\beta$-stimulated VEGF release was dose-dependent in the range between 10 and $50 \mu \mathrm{M}$ (Fig. 2). The maximum inhibitory effect of resveratrol was observed at $50 \mu \mathrm{M}$, which caused an $\sim 70 \%$ decrease in the TGF- $\beta$-effect.

Effect of SRT1720 on the TGF- $\beta$-stimulated VEGF release in MC3T3-E1 cells. It has been demonstrated that resveratrol activates SIRT1, resulting in the exertion of the biological effects $(11,12)$. Thus, the effect of SRT1720, which is a synthetic SIRT1 activator (23), was then examined on the TGF- $\beta$-stimulated VEGF release in MC3T3-E1 cells. SRT1720 reduced the TGF- $\beta$-stimulated VEGF release in a time-dependent manner (Fig. 3A). In addition, SRT1720 decreased the TGF- $\beta$-induced VEGF release in a dose-dependent manner (Fig. 3B). The inhibitory effect of SRT1720 that was observed at $3 \mu \mathrm{M}$ on the VEGF release caused an $\sim 60 \%$ decrease in the TGF- $\beta$-effect.

Effects of resveratrol or SRT1720 on the TGF- $\beta$-induced expression levels of VEGF mRNA in MC3T3-E1 cells. In order to investigate whether or not the suppressive effect of resveratrol or SRT1720 on the TGF- $\beta$-stimulated VEGF release was mediated through transcriptional events, the effect of resveratrol or SRT1720 on the TGF- $\beta$-induced VEGF mRNA expression levels was further examined using RT-qPCR. Although resveratrol by itself had little effect on the mRNA levels of VEGF, it significantly suppressed the mRNA expression levels induced by TGF- $\beta$ (Fig. 4A). Additionally, SRT1720 markedly reduced the VEGF mRNA expression levels stimulated by TGF- $\beta$ in a similar manner to resveratrol (Fig. 4B).

Effect of resveratrol on the TGF- $\beta$-induced phosphorylation of Smad in MC3T3-E1 cells. It is generally recognized that the effect of TGF- $\beta$ is mainly mediated through the Smad-dependent pathway (24). It was found that Smad is involved in the TGF- $\beta$-stimulated VEGF synthesis in osteoblasts. In order to clarify whether the suppressive effect of resveratrol on the TGF- $\beta$-stimulated VEGF synthesis was mediated by the modulation of Smad activation in MC3T3-E1 cells, the effect of resveratrol on the TGF- $\beta$-induced phosphorylation of Smad2 was examined; however, it was demonstrated that resveratrol had little effect on the TGF- $\beta$-induced phosphorylation of Smad2 in the range between 10 and $50 \mu \mathrm{M}$ (Fig. 5).

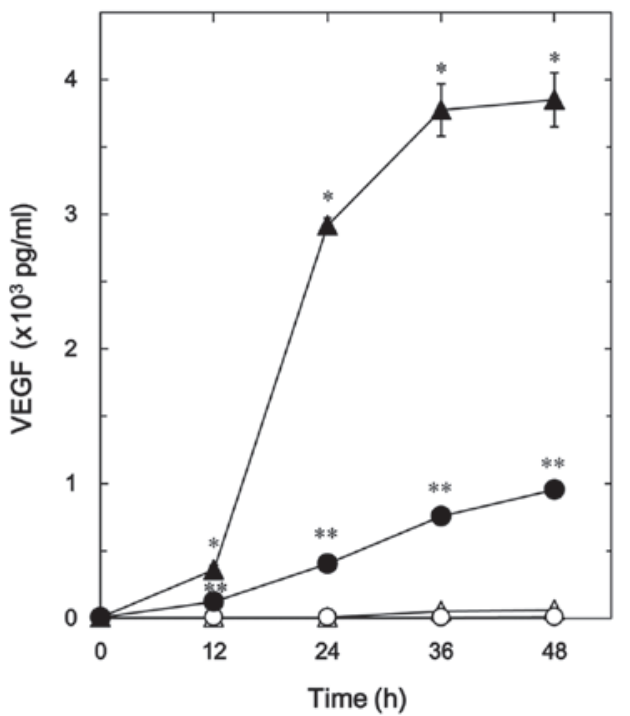

Figure 1. Effect of resveratrol on the TGF- $\beta$-stimulated VEGF release in MC3T3-E1 cells. The cultured cells were pretreated with $50 \mu \mathrm{M}$ resveratrol $(\bullet, \bigcirc)$ or vehicle $(\boldsymbol{\Lambda}, \triangle)$ for $60 \mathrm{~min}$, and then stimulated by $5 \mathrm{ng} / \mathrm{ml}$ TGF- $\beta(\bullet, \mathbf{\Delta})$ or vehicle $(O, \triangle)$ for the indicated periods. The VEGF concentrations of the conditioned media were determined by enzyme-linked immunosorbent assay. Each value represents the mean \pm standard error of the mean of triplicate determinations from three independent cell preparations. ${ }^{*} \mathrm{P}<0.05$, compared with the value of the control. ${ }^{* *} \mathrm{P}<0.05$, compared with the value of TGF- $\beta$ alone. TGF- $\beta$, transforming growth factor- $\beta$; VEGF, vascular endothelial growth factor.

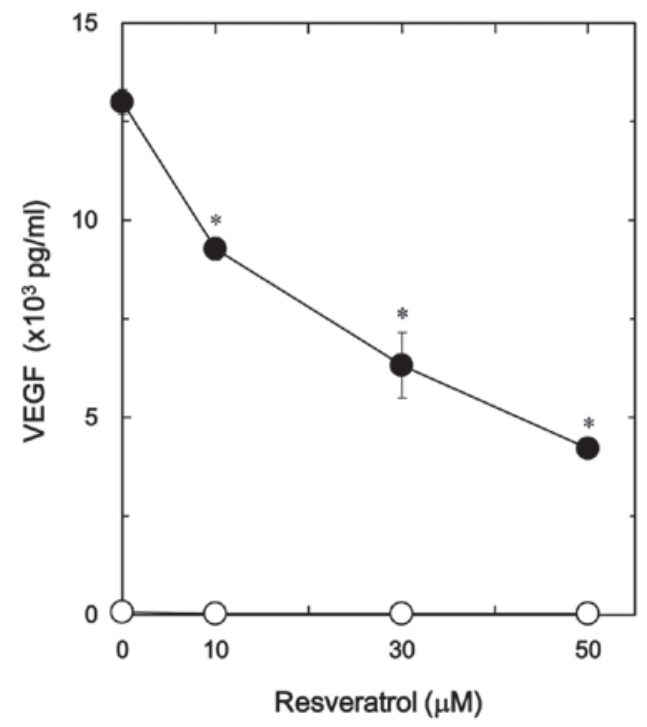

Figure 2. Effect of resveratrol on the TGF- $\beta$-stimulated VEGF release in MC3T3-E1 cells. The cultured cells were pretreated with various doses of resveratrol for $60 \mathrm{~min}$, and then stimulated by $5 \mathrm{ng} / \mathrm{ml} \mathrm{TGF}-\beta(\bullet)$ or vehicle $(\bigcirc)$ for $48 \mathrm{~h}$. VEGF concentrations of the conditioned media were determined by enzyme-linked immunosorbent assay. Each value represents the mean \pm standard error of the mean of triplicate determinations from three independent cell preparations. ${ }^{*} \mathrm{P}<0.05$, compared with the value of TGF- $\beta$ alone. TGF- $\beta$, transforming growth factor- $\beta$; VEGF, vascular endothelial growth factor.

Effect of resveratrol on the phosphorylation of p38 MAP kinase induced by TGF- $\beta$ in MC3T3-El cells. In our previous study it was reported that the TGF- $\beta$-induced VEGF synthesis in osteoblast-like MC3T3-E1 cells was 
A

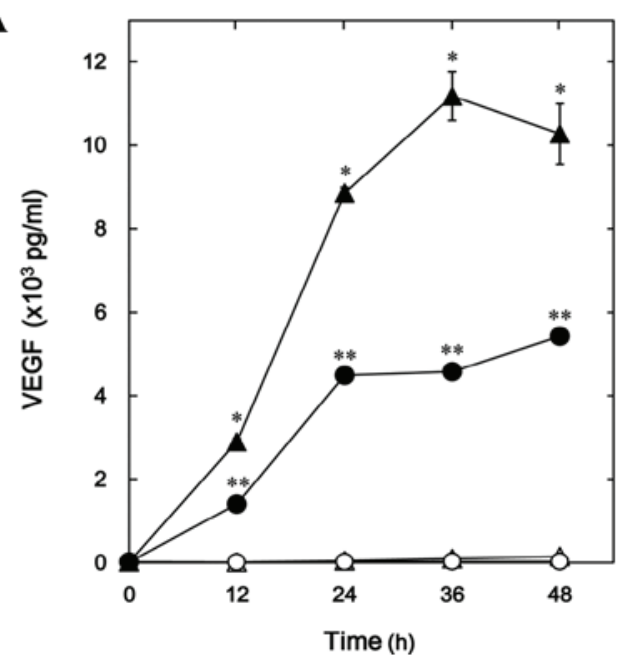

B

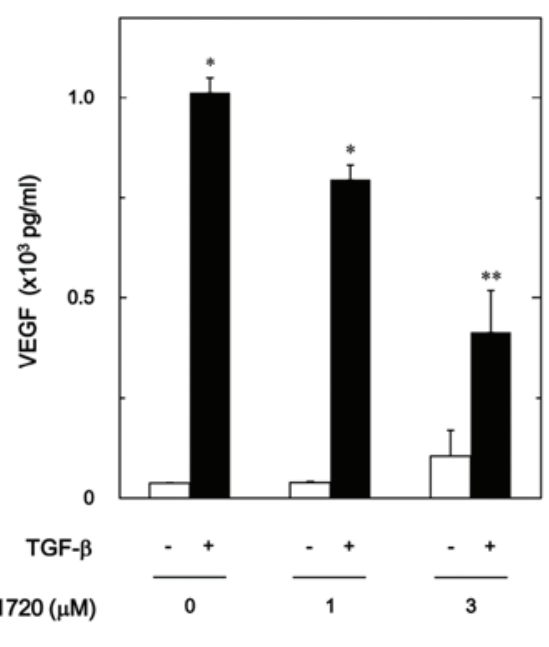

Figure 3. Effect of SRT1720 on the TGF- $\beta$-stimulated VEGF release in MC3T3-E1 cells. (A) The cultured cells were pretreated with $10 \mu$ M SRT1720 (๑,O) or vehicle $(\boldsymbol{\Lambda}, \triangle)$ for $60 \mathrm{~min}$, and then stimulated by $5 \mathrm{ng} / \mathrm{ml}$ TGF- $\beta(\mathbf{Q}, \mathbf{\Delta})$ or vehicle $(\mathrm{O}, \triangle)$ for the indicated periods. (B) The cultured cells were pretreated with various doses of SRT1720 for $60 \mathrm{~min}$, and then stimulated by $5 \mathrm{ng} / \mathrm{ml}$ TGF- $\beta$ or vehicle for $48 \mathrm{~h}$. VEGF concentrations of the conditioned media were determined by enzyme-linked immunosorbent assay. Each value represents the mean \pm standard error of the mean of triplicate determinations from three independent cell preparations. " $\mathrm{P}<0.05$, compared with the value of the control. ${ }^{* *} \mathrm{P}<0.05$, compared with the value of TGF- $\beta$ alone. TGF- $\beta$, transforming growth factor- $\beta$; VEGF, vascular endothelial growth factor.

A

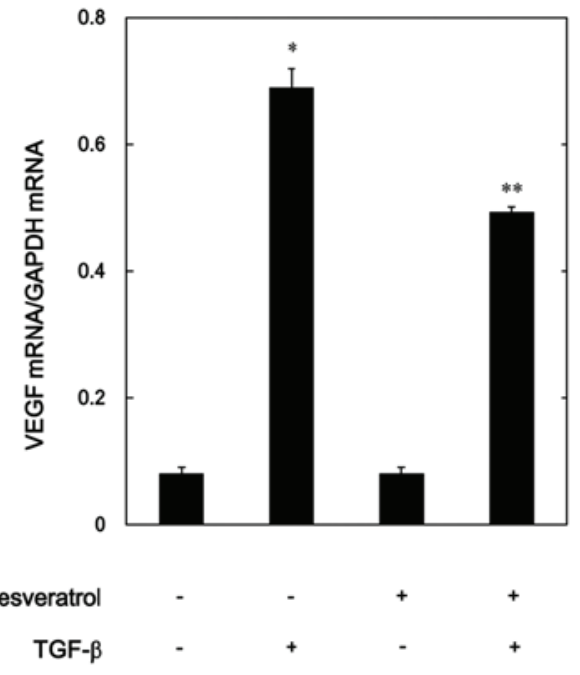

B

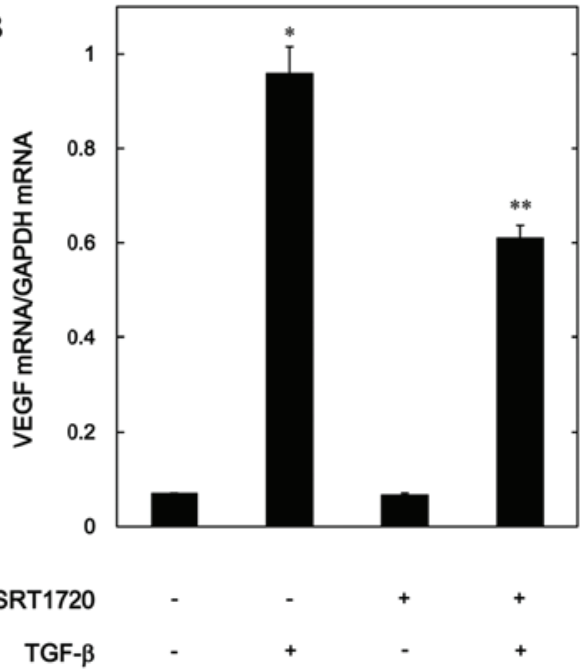

Figure 4. Effects of (A) resveratrol or (B) SRT1720 on the TGF- $\beta$-induced expression levels of VEGF mRNA in MC3T3-E1 cells. The cultured cells were pretreated with $50 \mu \mathrm{M}$ resveratrol, $10 \mu \mathrm{M}$ SRT1720 or vehicle for $60 \mathrm{~min}$, and then stimulated by $5 \mathrm{ng} / \mathrm{ml}$ TGF- $\beta$ or vehicle for $12 \mathrm{~h}$. The respective total RNA was then isolated and transcribed into cDNA. The expression of VEGF and GAPDH mRNA was quantified by the reverse transcription-quantitative polymerase chain reaction. The VEGF mRNA levels were normalized to those of GAPDH mRNA. Each value represents the mean \pm standard error of the mean of triplicate determinations from three independent cell preparations. ${ }^{*} \mathrm{P}<0.05$ compared with the value of the control. ${ }^{* *} \mathrm{P}<0.05$ compared with the value of TGF- $\beta$ alone. TGF- $\beta$, transforming growth factor- $\beta$; VEGF, vascular endothelial growth factor.

positively regulated by p38 MAP kinase, p44/p42 MAP kinase and SAPK/JNK $(9,10)$. The effect of resveratrol on the TGF- $\beta$-induced phosphorylation of $\mathrm{p} 38$ MAP kinase was therefore examined in the present study. The results showed that the phosphorylation of p38 MAP kinase stimulated by TGF- $\beta$ was not affected by resveratrol in the range between 10 and $50 \mu \mathrm{M}$ (Fig. 6).

Effect of resveratrol on the TGF- $\beta$-induced phosphorylation of p44/p42 MAP kinase and SAPK/JNK in MC3T3-E1 cells. To investigate whether the inhibitory effect of resveratrol on the TGF- $\beta$-stimulated VEGF synthesis was mediated through the modulation of p44/p42 MAP kinase and/or SAPK/JNK activation in MC3T3-E1 cells, the effect of resveratrol on the TGF- $\beta$-induced phosphorylation of p44/p42 MAP kinase or SAPK/JNK was examined. Resveratrol markedly suppressed the TGF- $\beta$-induced phosphorylation of p44/p42 MAP kinase in a dose-dependent manner in the range between 10 and $50 \mu \mathrm{M}$ (Fig. 7). In addition, as shown in Fig. 8, the phosphorylation of SAPK/JNK stimulated by TGF- $\beta$ was dose-dependently attenuated by resveratrol in the range between 10 and $50 \mu \mathrm{M}$. 

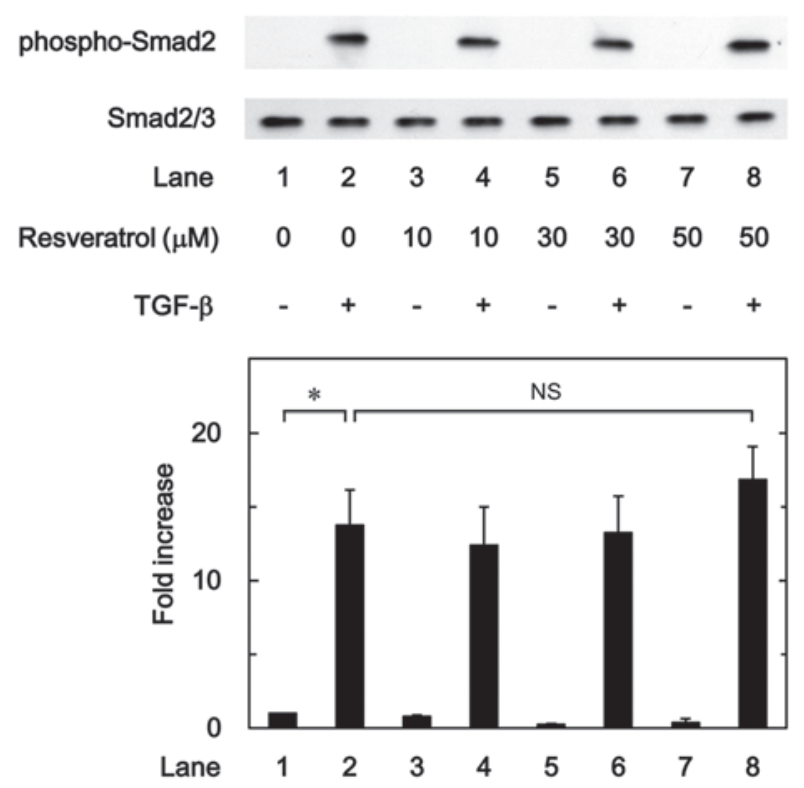

Figure 5. Effect of resveratrol on the TGF- $\beta$-induced phosphorylation of Smad in MC3T3-E1 cells. The cultured cells were pretreated with various doses of resveratrol for $60 \mathrm{~min}$, and then stimulated by $5 \mathrm{ng} / \mathrm{ml} \mathrm{TGF}-\beta$ or vehicle for $120 \mathrm{~min}$. The cell extracts were subsequently subjected to sodium dodecyl sulfate-polyacrylamide gel electrophoresis and western blot analysis with antibodies against phospho-specific Smad2 or Smad2/3. The histogram shows a quantitative representation of the levels of TGF- $\beta$-induced phosphorylation obtained from a laser densitometric analysis of three independent experiments. Each value represents the mean \pm standard error of the mean of triplicate determinations. " $\mathrm{P}<0.05$, compared with the value of the control. TGF- $\beta$, transforming growth factor- $\beta$; NS, not significant.
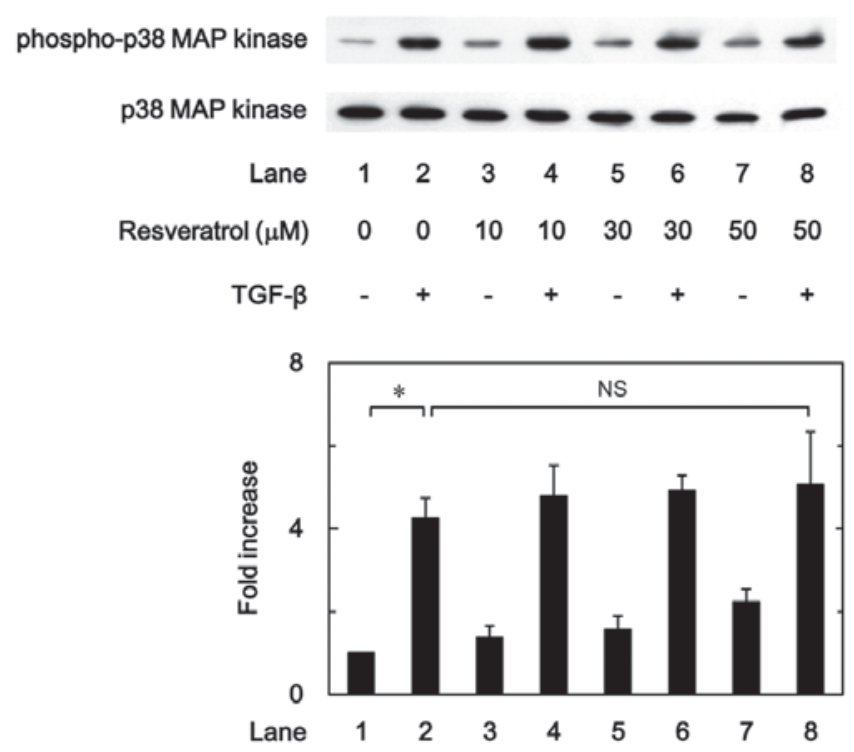

Figure 6. Effect of resveratrol on the TGF- $\beta$-induced phosphorylation of p38 MAP kinase in MC3T3-E1 cells. The cultured cells were pretreated with various doses of resveratrol for $60 \mathrm{~min}$, and then stimulated by $5 \mathrm{ng} / \mathrm{ml}$ TGF- $\beta$ or vehicle for $120 \mathrm{~min}$. The cell extracts were subsequently subjected to sodium dodecyl sulfate-polyacrylamide gel electrophoresis and western blot analysis with antibodies against phospho-specific p38 MAP kinase or p38 MAP kinase. The histogram shows a quantitative representation of the levels of TGF- $\beta$-induced phosphorylation obtained from a laser densitometric analysis of three independent experiments. Each value represents the mean \pm standard error of the mean of triplicate determinations. ${ }^{*} \mathrm{P}<0.05$, compared with the value of the control. TGF- $\beta$, transforming growth factor- $\beta$; MAP, mitogen-activated protein; NS, not significant.
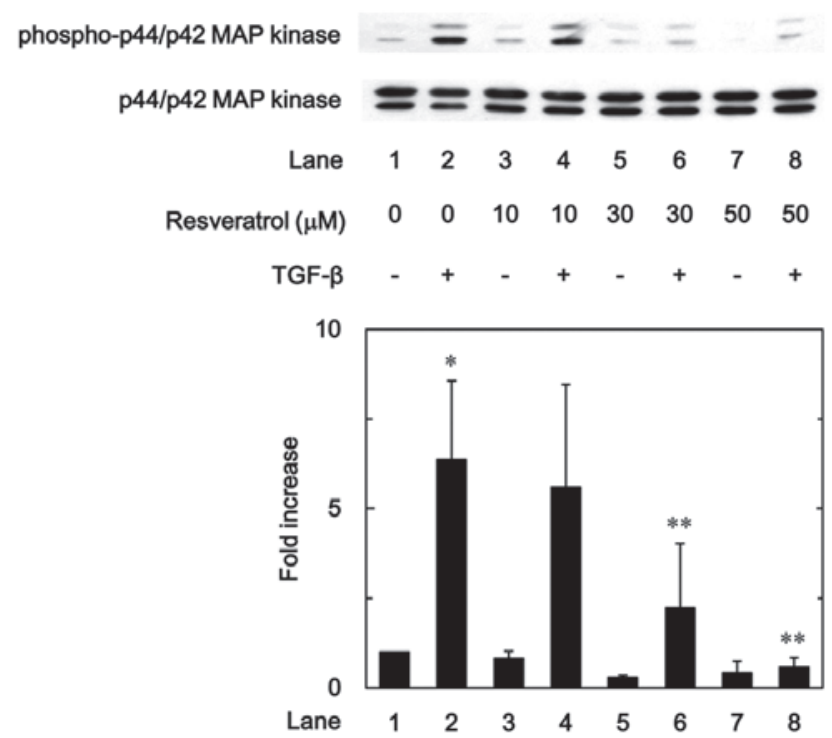

Figure 7. Effect of resveratrol on the TGF- $\beta$-induced phosphorylation of p44/p42 MAP kinase in MC3T3-E1 cells. The cultured cells were pretreated with various doses of resveratrol for $60 \mathrm{~min}$, and then stimulated by $5 \mathrm{ng} / \mathrm{ml}$ TGF- $\beta$ or vehicle for $120 \mathrm{~min}$. The cell extracts were subsequently subjected to sodium dodecyl sulfate-polyacrylamide gel electrophoresis and western blot analysis with antibodies against phospho-specific p44/p42 MAP kinase or $\mathrm{p} 44 / \mathrm{p} 42 \mathrm{MAP}$ kinase. The histogram shows a quantitative representation of the levels of TGF- $\beta$-induced phosphorylation obtained from a laser densitometric analysis of three independent experiments. Each value represents the mean \pm standard error of the mean of triplicate determinations. " $\mathrm{P}<0.05$, compared with the value of the control. ${ }^{* *} \mathrm{P}<0.05$, compared with the value of TGF- $\beta$ alone. TGF- $\beta$, transforming growth factor- $\beta$; MAP, mitogen-activated protein.
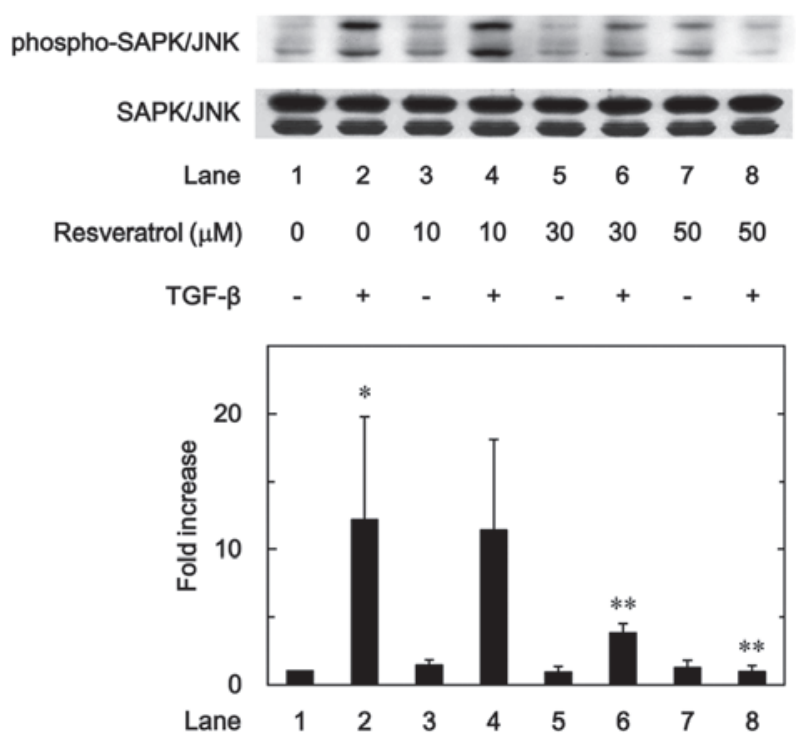

Figure 8 . Effect of resveratrol on the TGF- $\beta$-induced phosphorylation of SAPK/JNK in MC3T3-E1 cells. The cultured cells were pretreated with various doses of resveratrol for $60 \mathrm{~min}$, and then stimulated by $5 \mathrm{ng} / \mathrm{ml} \mathrm{TGF}-\beta$ or vehicle for $120 \mathrm{~min}$. The cell extracts were subsequently subjected to sodium dodecyl sulfate-polyacrylamide gel electrophoresis and western blot analysis with antibodies against phospho-specific SAPK/JNK or SAPK/JNK. The histogram shows a quantitative representation of the levels of TGF- $\beta$-induced phosphorylation obtained from a laser densitometric analysis of three independent experiments. Each value represents the mean \pm standard error of the mean of triplicate determinations. " $\mathrm{P}<0.05$, compared with the value of the control. ${ }^{* *} \mathrm{P}<0.05$, compared with the value of TGF- $\beta$ alone. TGF- $\beta$, transforming growth factor- $\beta$; SAPK/JNK, stress-activated protein kinase/c-Jun $\mathrm{N}$-terminal kinase. 

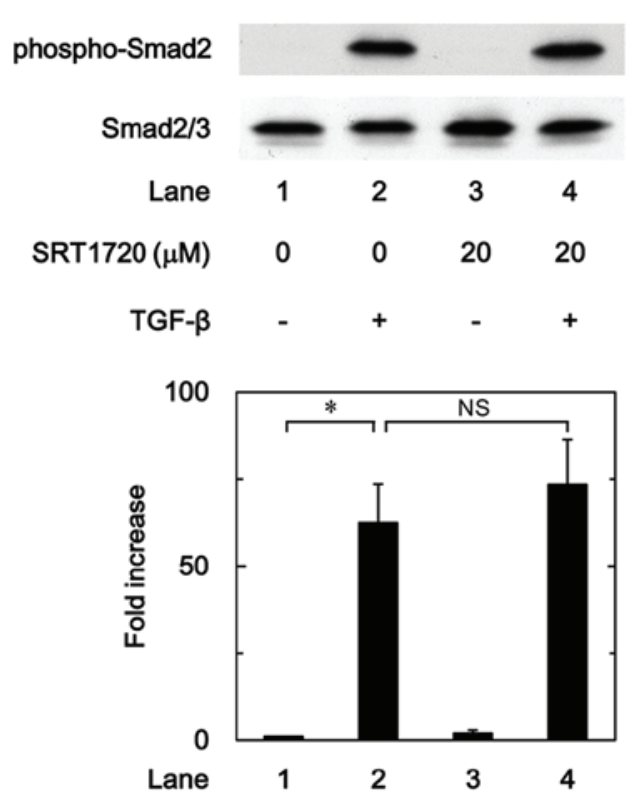

C
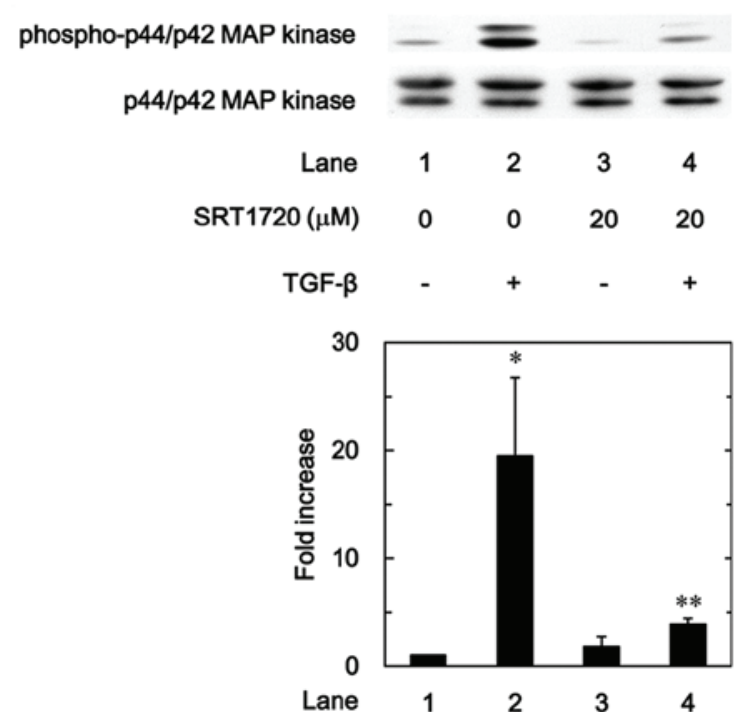

\section{B}
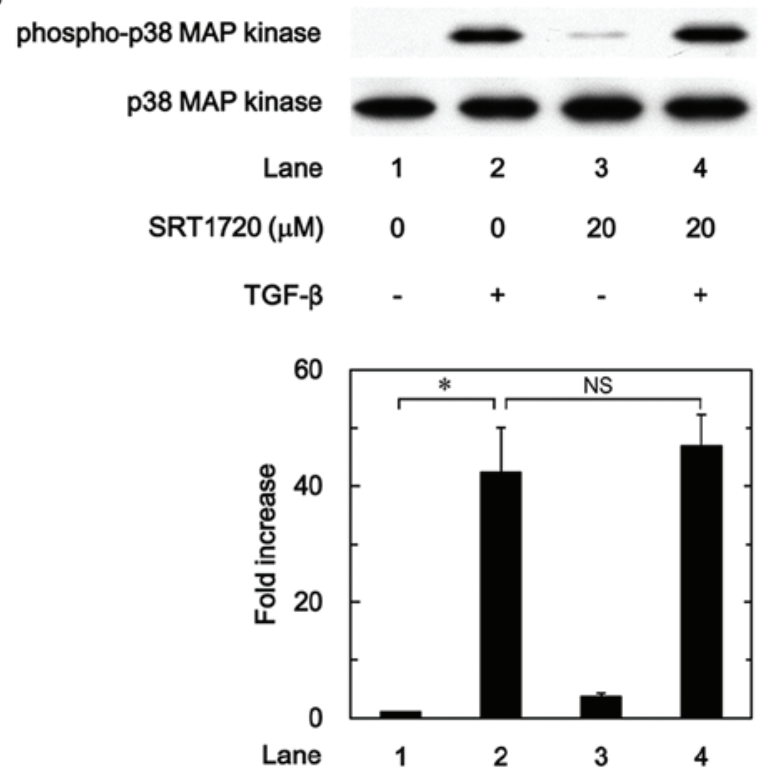

D
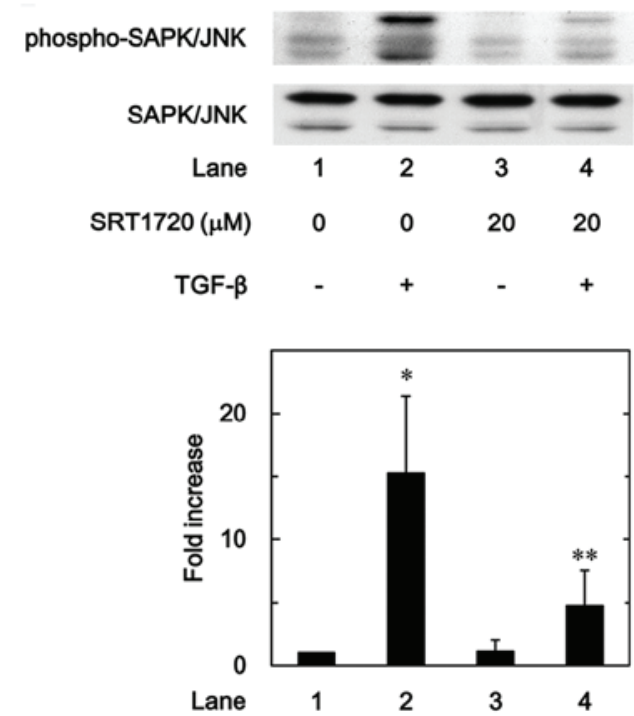

Figure 9. Effects of SRT1720 on the TGF- $\beta$-induced phosphorylation of (A) Smad, (B) p38 MAP kinase, (C) p44/p42 MAP kinase or (D) SAPK/JNK in MC3T3-E1 cells. The cultured cells were pretreated with $20 \mu \mathrm{M}$ SRT1720 for $60 \mathrm{~min}$, and then stimulated by $5 \mathrm{ng} / \mathrm{ml}$ TGF- $\beta$ or vehicle for $120 \mathrm{~min}$. The cell extracts were subsequently subjected to sodium dodecyl sulfate-polyacrylamide gel electrophoresis and western blot analysis with antibodies against phospho-specific Smad2, Smad2/3, phospho-specific p38 MAP kinase, p38 MAP kinase, phospho-specific p44/p42 MAP kinase, p44/p42 MAP kinase, phospho-specific SAPK/JNK or SAPK/JNK. The histograms show a quantitative representation of the levels of TGF- $\beta$-induced phosphorylation obtained from a laser densitometric analysis of three independent experiments. Each value represents the mean \pm standard error of the mean of triplicate determinations. ${ }^{* *} \mathrm{P}<0.05$, compared with the value of the control. ${ }^{* *} \mathrm{P}<0.05$, compared with the value of TGF- $\beta$ alone. TGF- $\beta$, transforming growth factor- $\beta$; SAPK/JNK, stress-activated protein kinase/c-Jun N-terminal kinase; MAP, mitogen-activated protein; NS, not significant.

Effect of SRT1720 on the TGF- $\beta$-induced phosphorylation of Smad, p38 MAP kinase, p44/p42 MAP kinase or SAPK/JNK in MC3T3-E1 cells. The effects of SRT1720 on the TGF- $\beta$-induced phosphorylation of Smad2, p38 MAP kinase, $\mathrm{p} 44 / \mathrm{p} 42$ MAP kinase or SAPK/JNK in osteoblast-like MC3T3-E1 cells were further investigated. SRT1720 hardly affected the TGF- $\beta$-induced phosphorylation of Smad2 or p38 MAP kinase (Fig. 9A and B); however, SRT1720 significantly suppressed the TGF- $\beta$-induced phosphorylation of p44/p42 MAP kinase or SAPK/JNK (Fig. 9C and D). Thus, the present findings suggest that SRT1720 mimics the effects of resveratrol on the TGF- $\beta$-induced phosphoryla- tion of Smad2, p38 MAP kinase, p44/p42 MAP kinase and SAPK/JNK.

\section{Discussion}

In the present study, it was demonstrated that resveratrol, a polyphenolic compound found in grape and berry skins and red wine, significantly suppressed the TGF- $\beta$-stimulated release of VEGF in osteoblast-like MC3T3-E1 cells. It was additionally found that SRT1720, an activator of SIRT1 with a potency 1,000 times greater than that of resveratrol (23), markedly reduced the VEGF release induced by TGF- $\beta$ in these 
cells. Resveratrol has been shown to induce the activation of SIRT1 and extend the life span of yeast and mammalian mouse models $(25,26)$; therefore, it is possible that the inhibitory effect of resveratrol on the TGF- $\beta$-induced VEGF release is mediated, at least to a certain extent, by the activation of SIRT1 in MC3T3-E1 cells. In addition, it was observed that resveratrol and SRT1720 reduced the expression levels of VEGF mRNA following their upregulated by TGF- $\beta$ in those cells. Based on these findings, it is most likely that the suppressive effect of resveratrol on the TGF- $\beta$-stimulated VEGF synthesis is exerted at a point upstream of the transcriptional level in osteoblast-like MC3T3-E1 cells.

The TGF- $\beta$ super family includes TGF- $\beta$, BMPs and activin (4). TGF- $\beta$ signaling is a simple linear cascade involving the TGF- $\beta$ ligands, the Smad signal transducers and two types of receptors (type I and II). The Smad complex directly binds to particular elements of the DNA and regulates the expression of the target gene (4). The present study showed that the TGF- $\beta$-induced phosphorylation of Smad 2 was not affected by resveratrol in MC3T3-E1 cells; therefore, it is unlikely that the effect of resveratrol observed was mediated through the Smad-dependent pathway in osteoblast-like MC3T3-E1 cells. It has been previously recognized, however, that the effects of TGF- $\beta$ are also exerted through the Smad-independent pathways, such as the MAP kinase pathway (27). We have previously shown that TGF- $\beta$ upregulates the synthesis of VEGF through the activation of p38 MAP kinase, p44/p42 MAP kinase and SAPK/JNK in osteoblast-like MC3T3-E1 cells $(9,10)$. Thus, in the present study it was examined whether resveratrol could affect the phosphorylation of p38 MAP kinase, p44/p42 MAP kinase or SAPK/JNK induced by TGF- $\beta$ in these cells. Although resveratrol failed to affect the TGF- $\beta$-induced phosphorylation of p38 MAP kinase, the phosphorylation of both p44/p42 MAP kinase and SAPK/JNK stimulated by TGF- $\beta$ was significantly reduced by resveratrol in the MC3T3-E1 cells. Based on these findings, it is most likely that the suppressive effect of resveratrol on the TGF- $\beta$-stimulated VEGF synthesis is mediated by the inhibition of both p44/p42 MAP kinase and SAPK/JNK in osteoblast-like MC3T3-E1 cells. In addition, it was observed that SRT1720 reduced the phosphorylation of p44/p42 MAP kinase and SAPK/JNK without affecting the phosphorylation of Smad 2 or p38 MAP kinase, suggesting that the described inhibitory effect of resveratrol is mediated via the activation of SIRT1 in osteoblast-like MC3T3-E1 cells. A potential mechanism underlying the action of resveratrol on the TGF- $\beta$-stimulated VEGF synthesis in osteoblasts is summarized in Fig. 10.

TGF- $\beta$ has a stimulatory effect on osteoblastic bone formation (5). TGF- $\beta$ reportedly functions as an autacoid in osteoblasts, and modulates cellular functions, including VEGF production (8). VEGF is an essential mediator of angiogenesis, and plays a pivotal role in the process of bone formation and fracture healing (8). During bone fracture repair, osteoclasts produce heparinase, an enzyme promoting the release of VEGF from heparin in an active form, and contribute to local angiogenesis, osteoclast formation and callus resorptive activities (5). Callus resorption is one of the essential steps initiating the process of bone formation. With regard to the favorable effect of resveratrol on the human health, particularly bone health (14), it is possible that the suppressive effect of resveratrol on the TGF- $\beta$-induced VEGF synthesis in osteoblasts provides

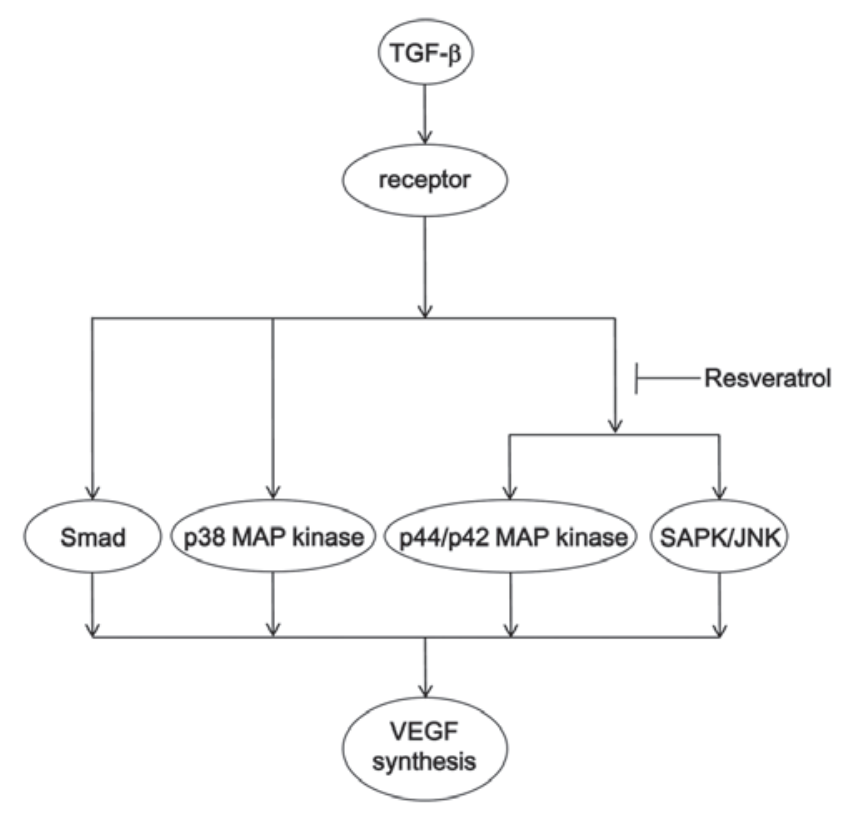

Figure 10. Schematic illustration of the regulatory mechanism underlying the TGF- $\beta$-induced synthesis of VEGF and the inhibitory effect of resveratrol in osteoblast-like MC3T3-E1 cells. TGF- $\beta$, transforming growth factor- $\beta$; SAPK/JNK, stress-activated protein kinase/c-Jun N-terminal kinase; MAP, mitogen-activated protein; VEGF, vascular endothelial growth factor.

adequate vascularization for the process of bone remodeling. Appropriate vascularization is required in the regulation of bone turnover, and adequate VEGF synthesis is considered to be essential for maintaining both the quality and the quantity of bone mass. These findings concerning the inhibitory effect of resveratrol on the TGF- $\beta$-stimulated VEGF synthesis in osteoblasts may provide new information about the role of VEGF as a 'gate keeper' of bone tissue quality via the regulation of bone remodeling. Further investigation is necessary to determine the exact mechanism through which resveratrol affects VEGF synthesis in osteoblasts. In conclusion, the present findings strongly suggest that the TGF- $\beta$-stimulated VEGF synthesis is suppressed by resveratrol through the inhibition of p44/p42 MAP kinase and SAPK/JNK in osteoblasts, and that the inhibitory effect is exerted, at least in part, via SIRT1 activation.

\section{Acknowledgements}

This investigation was supported in part by the Grant-in-Aid for Scientific Research (no. 19591042) from the Ministry of Education, Science, Sports and Culture of Japan and Research Funding for Longevity Sciences (no. 23-9, 25-4) from the National Center for Geriatrics and Gerontology, Japan. The authors would like to thank Yumiko Kurokawa for her skillful technical assistance.

\section{References}

1. Kular J, Tickner J, Chim SM and Xu J: An overview of the regulation of bone remodelling at the cellular level. Clin Biochem 45: 863-873, 2012.

2. Chim SM, Tickner J, Chow ST, Kuek V, Guo B, Zhang G, Rosen V, Erber W and Xu J: Angiogenic factors in bone local environment. Cytokine Growth Factor Rev 24: 297-310, 2013. 
3. Parfitt AM: Targeted and nontargeted bone remodeling: Relationship to basic multicellular unit origination and progression. Bone 30: 5-7, 2002.

4. Moustakas A and Heldin $\mathrm{CH}$ : The regulation of TGFbeta signal transduction. Development 136: 3699-3714, 2009.

5. Tang Y, Wu X, Lei W, Pang L, Wan C, Shi Z, Zhao L, Nagy TR, Peng $\mathrm{X}, \mathrm{Hu} \mathrm{J}$, et al: TGF-beta1-induced migration of bone mesenchymal stem cells couples bone resorption with formation. Nat Med 15: 757-765, 2009

6. Karsenty G and Wagner EF: Reaching a genetic and molecular understanding of skeletal development. Dev Cell 2: 389-406, 2002.

7. Zhen $\mathrm{G}$ and Cao X: Targeting TGF $\beta$ signaling in subchondral bone and articular cartilage homeostasis. Trends Pharmacol Sci 35: 227-236, 2014

8. Clarkin CE and Gerstenfeld LC: VEGF and bone cell signalling: An essential vessel for communication? Cell Biochem Funct 31 $1-11,2013$

9. Tokuda H, Hatakeyama D, Akamatsu S, Tanabe K, Yoshida M, Shibata T and Kozawa O: Involvement of MAP kinases in TGF-beta-stimulated vascular endothelial growth factor synthesis in osteoblasts. Arch Biochem Biophys 415: 117-125, 2003.

10. Kanno Y, Ishisaki A, Yoshida M, Tokuda H, Numata O and Kozawa O: SAPK/JNK plays a role in transforming growth factor-beta-induced VEGF synthesis in osteoblasts. Horm Metab Res 37: 140-145, 2005.

11. Blander G and Guarente L: The Sir2 family of protein deacetylases. Annu Rev Biochem 73: 417-435, 2004.

12. Koo SH and Montminy M: In vino veritas: A tale of two sirt1s? Cell 127: 1091-1093, 2006.

13. Renaud S and de Lorgeril M: Wine, alcohol, platelets, and the French paradox for coronary heart disease. Lancet 339: 1523-1526, 1992.

14. Kubo JT, Stefanick ML, Robbins J, Wactawski-Wende J, Cullen MR, Freiberg M and Desai M: Preference for wine is associated with lower hip fracture incidence in post-menopausal women. BMC Womens Health 13: 36, 2013.

15. Kondo A, Otsuka T, Kuroyanagi G, Yamamoto N Matsushima-Nishiwaki R, Mizutani J, Kozawa O and Tokuda H: Resveratrol inhibits BMP-4-stimulated VEGF synthesis in osteoblasts: Suppression of S6 kinase. Int J Mol Med 33: 1013-1018, 2014.
16. Kuroyanagi G, Tokuda H, Matsushima-Nishiwaki R, Kondo A, Mizutani J, Kozawa O and Otsuka T: Resveratrol suppresses prostaglandin $\mathrm{F}(2 \alpha)$-induced osteoprotegerin synthesis in osteoblasts: Inhibition of the MAP kinase signaling. Arch Biochem Biophys 542: 39-45, 2014.

17. Kuroyanagi G, Mizutani J, Kondo A, Yamamoto $\mathrm{N}$, Matsushima-Nishiwaki R, Otsuka T, Kozawa O and Tokuda H: Suppression by resveratrol of prostaglandin D2-stimulated osteoprotegerin synthesis in osteoblasts. Prostaglandins Leukot Essent Fatty Acids 91: 73-80, 2014.

18. Sudo H, Kodama HA, Amagai Y, Yamamoto S and Kasai S: In vitro differentiation and calcification in a new clonal osteogenic cell line derived from newborn mouse calvaria. J Cell Biol 96: 191-198, 1983.

19. Kozawa O, Tokuda H, Miwa M, Kotoyori J and Oiso Y: Cross-talk regulation between cyclic AMP production and phosphoinositide hydrolysis induced by prostaglandin $\mathrm{E}_{2}$ in osteoblast-like cells. Exp Cell Res 198: 130-134, 1992.

20. Simpson DA, Feeney S, Boyle C and Stitt AW: Retinal VEGF mRNA measured by SYBR green I fluorescence: A versatile approach to quantitative PCR. Mol Vis 6: 178-183, 2000.

21. Laemmli UK: Cleavage of structural proteins during the assembly of the head of bacteriophage T4. Nature 227: 680-685, 1970.

22. Kato K, Ito H, Hasegawa K, Inaguma $\mathrm{Y}$, Kozawa $\mathrm{O}$ and Asano T: Modulation of the stress-induced synthesis of hsp27 and alpha B-crystallin by cyclic AMP in C6 rat glioma cells. J Neurochem 66: 946-950, 1996.

23. Milne JC, Lambert PD, Schenk S, et al: Small molecule activators of SIRT1 as therapeutics for the treatment of type 2 diabetes. Nature 450: 712-716, 2007.

24. Guo $X$ and Wang XF: Signaling cross-talk between TGF-beta/BMP and other pathways. Cell Res 19: 71-88, 2009.

25. Howitz KT, Bitterman KJ, Cohen HY, et al: Small molecule activators of sirtuins extend Saccharomyces cerevisiae lifespan. Nature 425: 191-196, 2003.

26. Baur JA, Pearson KJ, Price NL, et al: Resveratrol improves health and survival of mice on a high-calorie diet. Nature 444: 337-342, 2006.

27. Moustakas A and Heldin CH: Non-Smad TGF-beta signals. J Cell Sci 118: 3573-3584, 2005. 